\title{
Continuous Fiber Reinforced Composites from Anisoprint: How New Materials and Technologies Can Change Manufacturing
}

\author{
Fedor Antonov* \\ Luxembourg
}

ISSN: 2576-8840

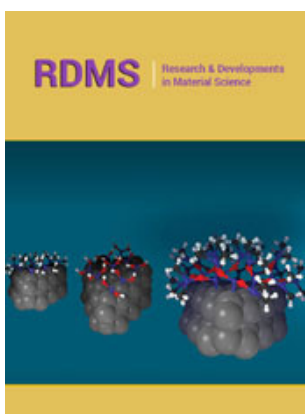

*Corresponding author: Fedor Antonov, 9 Avenue des Hauts Fourneaux, Esch-surAlzette L-4362, Luxembourg

Submission: 㭗 December 11, 2019

Published: 倹December 16, 2019

Volume 12 - Issue 3

How to cite this article: Fedor Antonov. Continuous Fiber Reinforced Composites from Anisoprint: How New Materials and Technologies Can Change Manufacturing. Res Dev Material Sci. 12(4). RDMS.000792.2019.

DOI: 10.31031/RDMS.2019.12.000792

Copyright@ Fedor Antonov, This article is distributed under the terms of the Creative Commons Attribution 4.0 International License, which permits unrestricted use and redistribution provided that the original author and source are credited.

\section{Opinion}

Anisoprint, manufacturer of continuous carbon fiber 3D printers and materials, launches new material - Composite Basalt Fiber (CBF). Parts reinforced with this material by anisoprinting technology have better properties than their counterparts from metal or plastic: 15 times stronger than plastic, 5 times lighter than steel, 1.5 times stronger and lighter than aluminium. Anisoprintint technology is based on Composite Fiber Co-extrusion process .

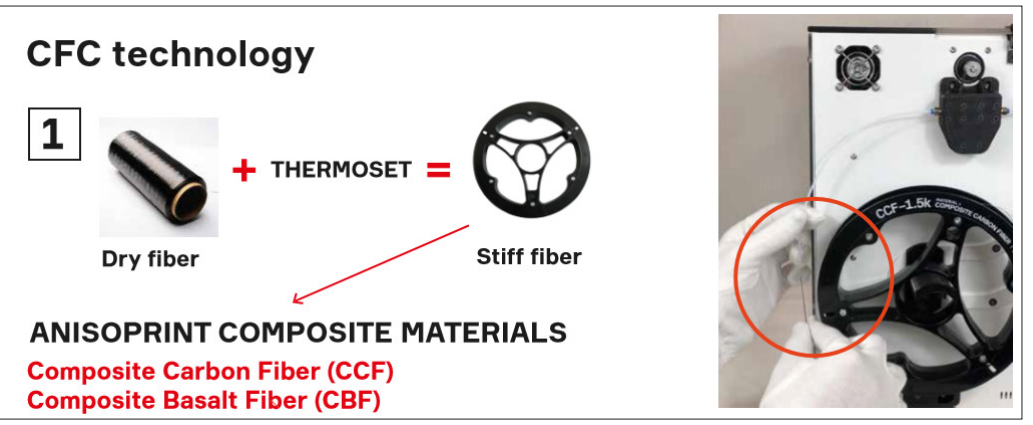

Figure 1: Bidentate

Reinforcing material is made from dry continuous fibers (carbon or basalt) preliminary impregnated with the special polymer mix. They're called Composite Fibers since they are already composites. Pre-impregnation provides low porosity and gives a good adhesion of reinforcing material to thermoplastic during the further printing process.

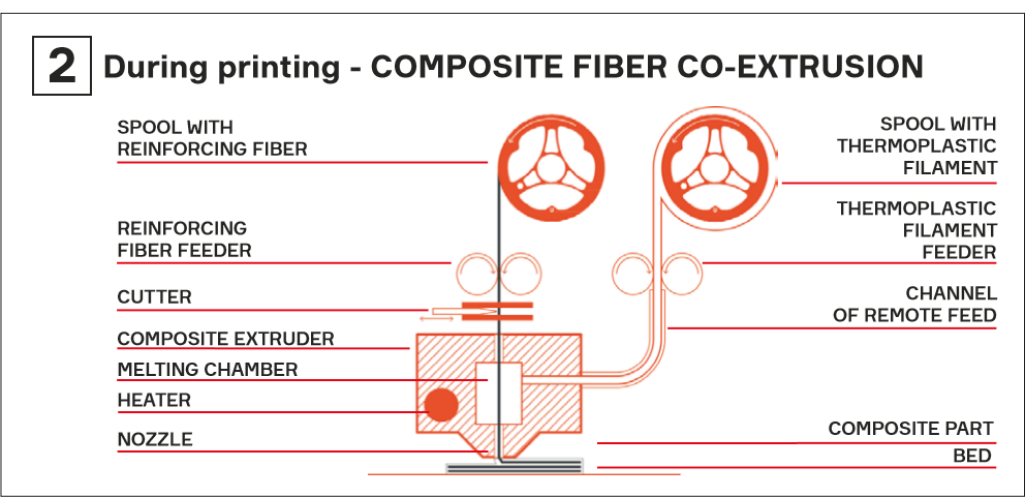

Figure 2: Bidentate

During the printing thermoplastic is reinforced with composite fiber. Composite extruder has two inputs: one for reinforcing material and the other for thermoplastic. Reinforcing fiber and plastic go separately in the same extruder so you can vary fiber volume ratio and lay it by complex curvilinear trajectories. In this way, it's possible to print composite parts of complex shapes with lattice inner structure that is the optimal form for composites due to their unidirectionality. 
Strength and stiffness of the composite lay along the fiber that's why the lattices which consist of one-dimensional ribs are the optimal shape for composites. With the composite infills, you can get maximum characteristics while wasting minimum material that means minimum weight, production time and price of the part

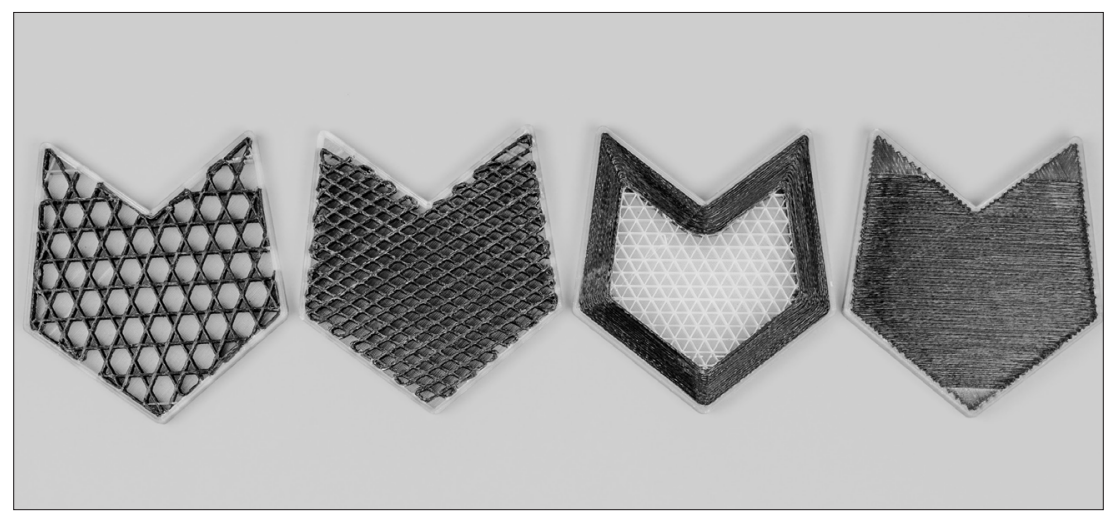

Figure 3: Bidentate

Let's consider the use case from Anisoprint products user experience. Helicopter factory needs a mold for sheet metal forming. The die must bear 400 bar pressure. Plywood's - traditional material - lifespan is too short. The metal die would work longer but costs significantly more. The best option to extend a lifespan and reduce costs is to print a die reinforced with continuous fibers.

The die from ULTEM was printed and compared to another two dies from PETG plastic reinforced with CCF and CBF materials printed on an Anisoprint Composer 3D printer. In case of anisoprinted parts only $30 \%$ of composite infill is enough to resist the required 400 bar pressure. Thus, it's possible to use minimum amount of material for required strength significantly decreasing costs. One can choose higher infill density or different plastics to satisfy the required loading conditions.

Figure 4: Bidentate

Table 1.

\begin{tabular}{|c|c|c|c|}
\hline & ULTEM & PETG + CCF & PETG + CBF \\
& (High Performance Plastic) & (Composite Carbon Fiber) & $30 \%$ composite isogrid infill \\
\hline \multirow{2}{*}{ Pressure } & $100 \%$ plastic infill & $30 \%$ composite isogrid infill & - Increase Strength \\
400 bar & - Strength Limit & - Increase Strength & by Raising Infill Density \\
\hline Price & $€ 300$ & by Raising Infill Density & $€ 80$ \\
\hline
\end{tabular}

For now, Anisoprint has two reinforcing materials: Composite Carbon Fiber (CCF) and Composite Basalt Fiber (CBF). During printing, the reinforcing fiber is combined with a wide range of plastics (PETG, ABS, PC, PLA, Nylon, etc). Plastic reinforced with
Anisoprint materials has up to $900 \mathrm{MPa}$ tensile strength while the density is $1.4 \mathrm{~g} / \mathrm{cm}^{3}$, which is up to 2 times lighter than aluminium. So, you get strong and lightweight parts that are several times cheaper and have desired chemical, thermal, surface properties. 
Basalt has one more feature - radio transparency. Parts made of composite basalt fiber don't significantly alter the amplitude and phase of radio-frequency electromagnetic waves transmitted through it. It's the best option for any non-conductive elements and insulators.

Parts printed from Composite basalt fiber or composite carbon fiber - stamps, brackets, fittings, orthoses, etc - can be used in a variety of areas: aerospace, automotive, healthcare, manufacturing, sport, transport - every area where high strength and lightweight are required. Such composites can bring significant changes both to research and industrial areas giving new properties to the usual materials and making objects from them more optimal.

For possible submissions Click below: 